\title{
Factors controlling production in hydraulically fractured low permeability oil reservoirs
}

\author{
Palash Panja* \\ Department of Chemical Engineering, \\ University of Utah, \\ 50 South Central Campus Drive, 3290 MEB, \\ Salt Lake City, Utah, 84102, USA \\ Fax: (+1-801)581-8692 \\ Email: ppanja@egi.utah.edu \\ *Corresponding author

\section{Tyler Conner} \\ Devon Energy, \\ 333 West Sheridan Avenue, Oklahoma City, \\ Oklahoma 73102-5015, USA \\ Email: Tyler.Conner@dvn.com

\section{Milind Deo} \\ Department of Chemical Engineering, \\ University of Utah, \\ 50 South Central Campus Drive, 3290 MEB, \\ Salt Lake City, Utah, 84102, USA \\ Fax: (+1-801)581-8692 \\ Email: milind.deo@utah.edu
}

\begin{abstract}
Fundamentals of fluid flow in ultra-low permeability reservoirs need to be examined to understand production behaviours. In this paper, we perform sensitivity studies of reservoir properties (matrix permeability, heterogeneity, rock compressibility and reservoir pressure), fluid properties (bubble point pressure and initial dissolved gas oil ratio), rock fluid properties (relative permeabilities), completion parameters (fracture spacing) and operating parameters (bottom hole pressure) on production performances. Matrix permeability, rock compressibility, fluid properties and fracture spacing have major impact on oil recovery and gas oil ratio (GOR). More oil is recovered from higher permeability reservoir in the expense of higher GOR. Recovery increases with increasing rock compressibility since the pressure decline is more gradual in higher compressibility rocks. Oil phase becomes less viscous and more mobile due to higher amount of dissolved gas. Higher initial GOR improves production of oil with higher produced GOR. Closer fracture spacing yields more oil recovery. [Received: April 2, 2015; Accepted: August 26, 2015]
\end{abstract}

Keywords: hydraulic fracture; shales; sensitivity studies; oil rate; gas oil ratio; GOR; recovery factor. 
Reference to this paper should be made as follows: Panja, P., Conner, T. and Deo, M. (2016) 'Factors controlling production in hydraulically fractured low permeability oil reservoirs', Int. J. Oil, Gas and Coal Technology, Vol. 13, No. 1, pp.1-18.

Biographical notes: Palash Panja is a Post-Doctoral Research Associate at Energy \& Geoscience Institute at the University of Utah. He worked for five years with a variety of companies from downstream to upstream production companies. His current interests include production from unconventional reservoirs such as shales, interactions between flow and thermodynamics, surrogate model development, and artificial intelligence. He received his MS degree from the Indian Institute of Technology, Bombay and his $\mathrm{PhD}$ degree from the University of Utah, both in Chemical Engineering.

Tyler Conner has worked as a Reservoir Engineer at Devon Energy for three years. Currently, he serves in a corporate function with the reservoir technology and optimisation team performing numerical simulation projects and developing training programs centred around rate transient analysis. He studied chemical engineering at the University of Utah, graduating in 2012. His research focus during his graduate studies revolved around numerical modelling and reservoir simulation of performance drivers in liquid rich unconventional reservoirs. He is active within SPE, currently serving on the board of the Oklahoma City Section as a Young Professional Chair.

Milind Deo is the Peter D. and Catherine R. Meldrum Endowed Professor and Chairman of the Department of Chemical Engineering at the University of Utah and Director of the Petroleum Research Center. He also was the Associate Dean for Academic Affairs for the U's College of Engineering from 2006 to 2013. He received his BS from the Indian Institute of Technology in Chennai, India and $\mathrm{PhD}$ from the University of Houston in Houston, TX in Chemical Engineering. His $\mathrm{PhD}$ research concentrated on the development of methods for determining residual fluid saturations after a carbon dioxide flood. After a short stay at the Schlumberger Perforating Center in Houston where he worked on under-balanced perforating technology, followed by two years of post-doctoral work at Stanford University, he joined the University of Utah in December 1989. His main areas of research at the University of Utah have been reservoir engineering and enhanced oil recovery.

\section{Introduction}

Flow behaviours of ultra-low permeability reservoirs are different from conventional reservoirs. For example, in conventional reservoirs, the gas oil ratios (GORs) rise quickly after the reservoir pressure has declined below the oil bubble point pressure, and reach peaks of 50 times the initial GORs under certain conditions (Muskat and Taylor, 1946). This GOR trend is markedly different for light tight oil (LTO) reservoirs, and will be explored in detail later in the paper. A number of studies have been conducted on undersaturated conventional reservoirs in primary production. Evinger and Muskat 
(1942) introduced the concept of theoretical productivity factor for solution gas drive reservoirs. Production rates for a given drawdown decreased as the solution GOR of the oil increased. Levine and Prats (1961) provided detailed calculations of performance of solution gas drive reservoirs. They used numerical simulators and showed the dependence of rate on permeability and recovery. They were also able to generalise rate versus drawdown for their set of parameters. These and other solutions are presented in the chapter on solution gas drive reservoirs in the Petroleum Engineering Handbook (Steffensen, 1987). For various cases presented here, the GOR goes through a maximum after starting out at the initial GOR. Sensitivities to such parameters as oil viscosities, permeability ratios, solution GOR, etc., were investigated. Vogel (1968) established an empirical relationship between flow rate and reservoir pressure for solution gas drive reservoirs using simulation results.

Researchers have investigated many factors which affect the production performance from conventional reservoirs as well as low permeable hydraulically fractured reservoir. Laboratory experiments showed that $30 \%$ to $100 \%$ errors were introduced on oil in place calculations for undersaturated conventional reservoirs (Hall, 1953) if the rock compressibility was neglected. The reservoir performance is very sensitive to the viscosity of reservoir fluids (Hernandez et al., 2002). Fracture spacing affects the performance of gas-oil gravity drainage largely when the ratio of fracture spacing and fracture height is larger than 0.3 (Clemens and Wit, 2001). Oil production increases with increase in fracture permeability up to $10,000 \mathrm{mD}$ and with increase in the fracture - matrix surface contact area (Orangi et al., 2011).

The impacts of fluid and rock properties like matrix permeability, rock compressibility, viscosity, specific gravity, oil formation volume factor (FVF) were investigated to study the sensitivity of the parameters on the recoverable oil and gas and recovery factors (Ling and Shen, 2011). Similar studies were conducted for oil production from unconventional reservoirs like Eagle Ford (Chaudhary et al., 2011). Chaudhary et al. (2011) considered the impact of matrix permeability, flowing bottom-hole pressure, fracture spacing, etc., on oil production from tight oil reservoirs. They did not consider many important properties like relative permeability, fluid PVT properties and rock compressibility in their study. In addition, simulation results were not compared to field data. In this study, a wide range of different factors are selected to study the impacts on oil production from ultra-low permeability reservoirs.

\section{Reservoir model}

Reservoir is fractured vertically in the middle with one horizontal well in the middle of the reservoir in the X-direction. The fracture is extended to the reservoir boundaries in Y-direction and Z-direction, i.e., height and fracture width are same as the reservoir height and width respectively. A schematic diagram of reservoir model is in Figure 1. 
Figure 1 The geometry and dimensions of the reservoir model (see online version for colours)

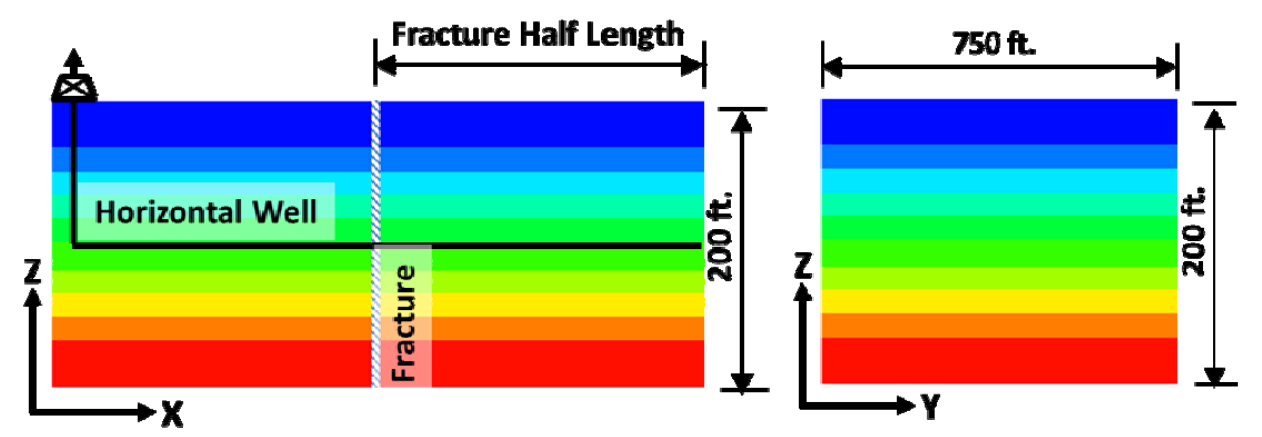

The reservoir width (Y-direction) is 750 feet and the reservoir height (Z-direction) is 200 feet. Width and height are considered constant for all simulations but the boundary in the X-direction is altered depending on the fracture spacing used in a particular simulation. The reservoir dimensions and other model properties are shown in Table 1.

Table 1 Reservoir and fracture parameters

\begin{tabular}{lc}
\hline Reservoir height $(\mathrm{ft})$ & 200 \\
Reservoir width(ft) & 750 \\
Fracture permeability $(\mathrm{mD})$ & $\mathrm{k}_{\mathrm{fx}}=\mathrm{k}_{\mathrm{fy}}=150 ; \mathrm{k}_{\mathrm{fz}}=300$ \\
Fracture width $(\mathrm{ft})$ & 0.05 \\
Fracture height $(\mathrm{ft})$ & Reservoir height \\
Fracture orientation & Parallel to YZ plane \\
Reservoir porosity: & $5 \%$ \\
\hline
\end{tabular}

Fracture width, fracture orientation, fracture permeability, reservoir temperature, reservoir porosity and initial hydrocarbon saturation remain constant. Initial reservoir pressure, flowing bottom hole pressure, fracture spacing vary in different studies. A wide range of matrix permeability $(50 \mathrm{nD}$ to $5,000 \mathrm{nD})$ is also considered.

Various cases are developed for sensitivity analysis of important factors. The name of each case, reservoir properties and operational parameters are listed in Table 2.

All simulations were conducted using IMEX, a computer modelling group black oil simulator. Prior to conducting the sensitivity studies, grid resolution studies (Panja et al., 2013) were performed to ensure that grid resolution did not have an effect on the results. Following parameters were considered in the sensitivity studies; matrix permeability, solution GOR and its dependence on pressure, relative permeability, formation compressibility, initial reservoir pressure, drawdown, fracture spacing and layered heterogeneity. In the following sections, we have discussed the effects of changing each of the parameters on production performance in terms of oil rate, cumulative oil or oil recovery and produced GOR. It is recognised that the phase behaviour and displacement mechanisms in nano porous media may be different. Complexities of phase behaviour changes and adsorption in nano pores are not accounted for in these simulations. 
Table 2 Reservoir and operational parameters used in different studies

\begin{tabular}{lcccc}
\hline Case & Name of study & $\begin{array}{c}\text { Initial pressure } \\
(\text { psi) }\end{array}$ & $\begin{array}{c}\text { BHP } \\
(\text { psi) }\end{array}$ & $\begin{array}{c}\text { Fracture half } \\
\text { length }(f t)\end{array}$ \\
\hline 1 & Matrix permeability & 5,300 & 1,500 & 1,000 \\
2 & Relative permeability & 4,500 & 500 & 150 \\
3 & Rock compressibility & 5,000 & 500 & 150 \\
4 & Fluid PVT & 4,500 & 500 & 150 \\
5 & Fracture spacing & 5,300 & 500 & $20,50,75,100,150$ \\
6 & Drawdown/overpressure & $4,500 / 5,500$ & $100,200,500$, & 150 \\
7 & & \multicolumn{4}{c}{$1,000,1,500,2,500$} & 150 \\
\hline
\end{tabular}

\section{Results and discussion}

\subsection{Effect of matrix permeability}

Matrix permeability is one of the most important parameters in the production of liquids from shales. Pressure profiles in the reservoir with time as functions of permeability provide insights on underlying production mechanisms. Average pressures as a function of time and pressure profile for black oil reservoirs are shown in Figure 2.

Figure 2 Pressure characteristics for different permeabilities, (a) average reservoir pressures with time (b) pressure profiles inside reservoir (see online version for colours)

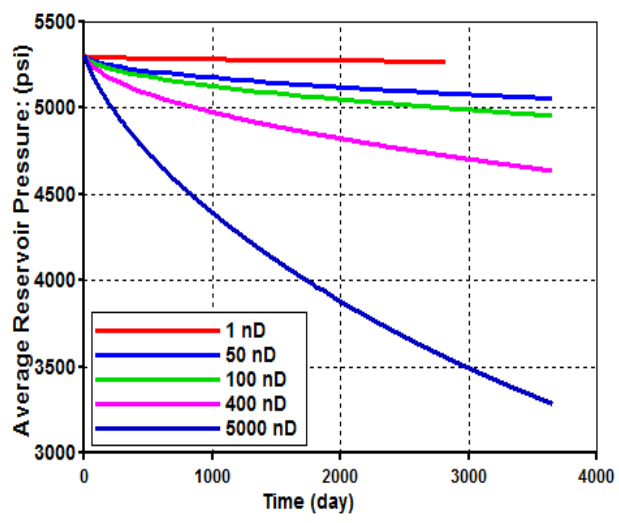

(a)

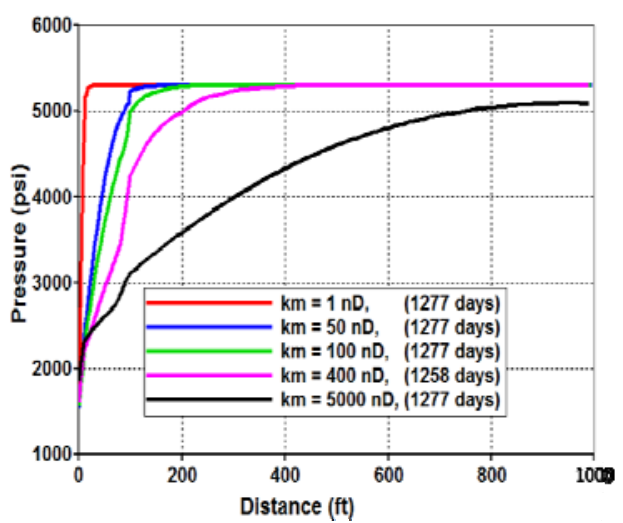

(b)

The reservoir remains in transient state for a considerable period of time until the boundaries are felt - either true boundaries or adjacent fractures. In transient state, most portions in the reservoir are at the initial pressure condition as shown in Figure 2(b). For ultra-low permeability reservoirs $(1 \mathrm{nD}$ to about $100 \mathrm{nD})$ there is little change in the average reservoir pressure from initial pressure, even though there is significant 
drawdown in the near fracture area. This underscores the fact that one needs to be careful when considering average properties using average pressure. The oil rate from simulation for permeabilities ranging from $1 \mathrm{nD}$ to $5,000 \mathrm{nD}$ and the oil rate are shown in Figure 3 for three different initial GORs.

Figure 3 (a) Oil rate (b) Cumulative GOR at different matrix permeabilities (see online version for colours)

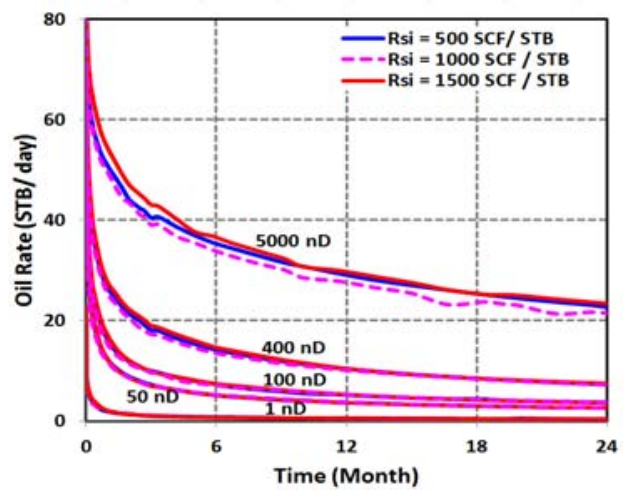

(a)

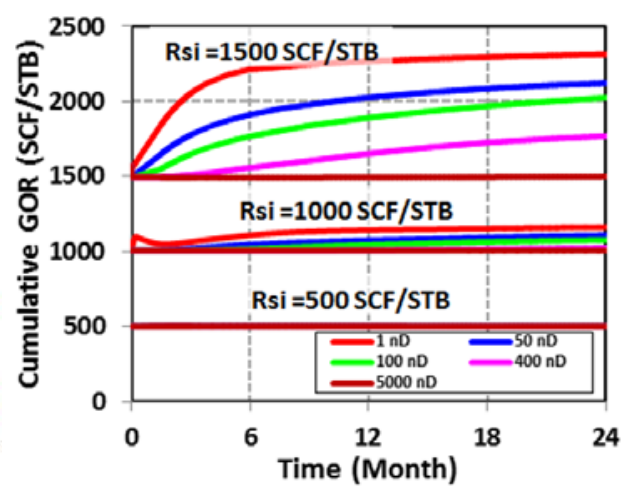

(b)

Similar trends were reported by Chaudhary et al. (2011). The oil rate for a $400 \mathrm{nD}$ reservoir (single fracture) is expected to be between $40 \mathrm{STB} /$ day to about $10 \mathrm{STB} /$ day in the first year. This depends on the drawdown, formation compressibility and a number of other factors. It is evident from the figures that the oil rate does not depend on initial GOR in the range of matrix permeability of $1 \mathrm{nD}$ to $5,000 \mathrm{nD}$. The figure also shows that the first-year decline rates vary considerably from about $60 \%$ for $5,000 \mathrm{nD}$ wells to about $85 \%$ for $100 \mathrm{nD}$ wells.

The GORs increase as the reservoir permeability decreases. The change is more significant at higher initial GOR whereas the change is negligible for lower initial GOR. This is a surprising result after having noted the slow average pressure decline in ultra-low permeability systems compared to the high permeability reservoirs. The reason for this may be the steep drawdown near the wellbore. Nevertheless, the shapes of the GOR curves are completely different from the ones observed for conventionals. The conventional wells with no hydraulic fracture display a constant GOR followed by a slight decrease below the bubble point (as the gas accumulates to residual gas saturation), followed by the rapid increase to very high GOR peak values before declining as the gas depletes. The LTO wells show a continuous, relatively smaller increase in GOR which plateaus at longer times. The value of this plateau increases as the permeability decreases.

It is seen that the pressure front does not move significantly outward even after about ten years of production as shown in Figure 2(b). For the $400 \mathrm{nD}$ case, the pressure front has propagated about 500 feet on each side of the fracture. The pressure does decrease below the bubble point $(2,750 \mathrm{psi})$ in the near fracture region. Only at the highest permeability $(5,000 \mathrm{nD})$, the pressure front reaches the boundary (1,000 feet away) after seven years and the pressure decreases below the initial reservoir pressure over the entire reservoir. It is the steep drawdown near the fracture that dominates the two-phase production behaviour. Steeper decline typically leads to higher GOR 
at lower permeabilities. Free gas is formed in the reservoir below the bubble point. The region of the existence of free gas is very small in the case of low permeabilities, however, the GORs are higher. This shows that the initial fluid enters the 'the flash chamber' near the wellbore and the steep pressure decline in that region determine the producing GOR.

\subsection{Effect of relative permeability}

The production of LTOs is characterised by understurated oil production in solution gas drive. It was noted that gas comes out of solution in a narrow zone near the fracture/matrix interface. The relative mobility of gas and oil depends on the gas-oil relative permeabilities. Various relative permeability curves are prepared for this study by varying exponent of Corey models. The Corey models for gas-oil system are given in equations (1) to (3).

$$
\begin{aligned}
& S^{*}=\frac{\left(S_{g}-S_{g c}\right)}{\left(1-S_{\text {org }}-S_{g c}\right)}, \\
& k_{r g}=k_{r w \text { at } S_{g c}}\left(S^{*}\right)^{n_{g}}, \\
& k_{\text {rog }}=k_{\text {rg at } S_{\text {org }}\left(1-S^{*}\right)^{n_{o}},}
\end{aligned}
$$

Relative permeability curves for water-oil systems are given in equations (4) to (6).

$$
\begin{aligned}
& S^{*}=\frac{\left(S_{w}-S_{w c}\right)}{\left(1-S_{\text {orw }}-S_{w c}\right)}, \\
& k_{r w}=k_{\text {rw at } S_{\text {orw }}\left(S^{*}\right)^{n_{w}},} \\
& k_{\text {row }}=k_{\text {ro at } S_{w c}}\left(1-S^{*}\right)^{n_{o}},
\end{aligned}
$$

\begin{tabular}{|c|c|c|c|c|c|c|c|c|}
\hline \multirow{2}{*}{ Case } & \multicolumn{4}{|c|}{ Water-oil system } & \multicolumn{4}{|c|}{ Gas-oil system } \\
\hline & $n_{w}$ & $n_{o}$ & $k_{r w}\left(S_{o r w}\right)$ & $k_{r o}\left(S_{w c}\right)$ & $n_{g}$ & $n_{o}$ & $k_{r w}\left(S_{g c}\right)$ & $k_{r g}\left(S_{\text {org }}\right)$ \\
\hline 1 & 3 & 3 & 0.6 & 1 & 1 & 1 & 1 & 1 \\
\hline 2 & 3 & 3 & 0.6 & 1 & 1 & 2 & 1 & 1 \\
\hline 3 & 3 & 3 & 0.6 & 1 & 1 & 3 & 1 & 1 \\
\hline 4 & 3 & 3 & 0.6 & 1 & 2 & 1 & 1 & 1 \\
\hline 5 & 3 & 3 & 0.6 & 1 & 3 & 1 & 1 & 1 \\
\hline
\end{tabular}

The end-point relative permeabilities were held constant during this study $\left(S_{g c}=0.1\right.$ and $\left.S_{\text {org }}=0.25\right)$. The five different cases studied are shown in Table 3 and the curves employed are shown in Figure 4.

Table 3 The relative permeability parameters used in the study 
Figure 4 Relative permeability curves for (a) water-oil two phase system and (b) gas-oil two phase system (see online version for colours)

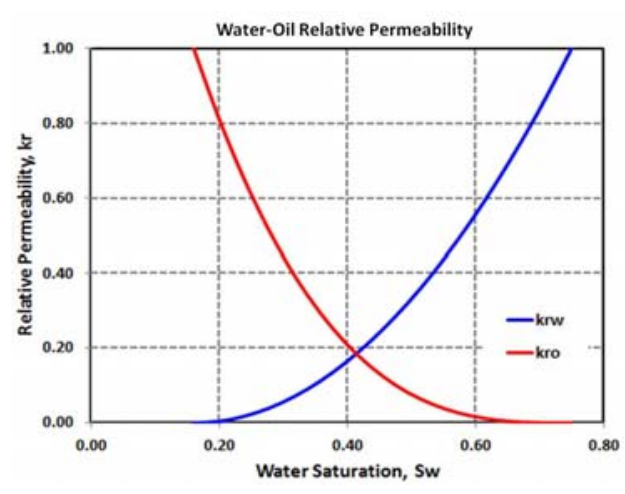

(a)

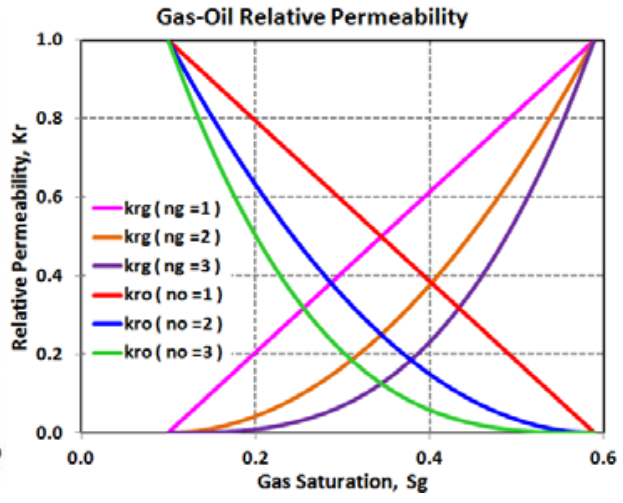

(b)

Figure 5 Cumulative oil for three different exponents of (a) oil relative permeabilities and (b) gas relative permeabilities (see online version for colours)

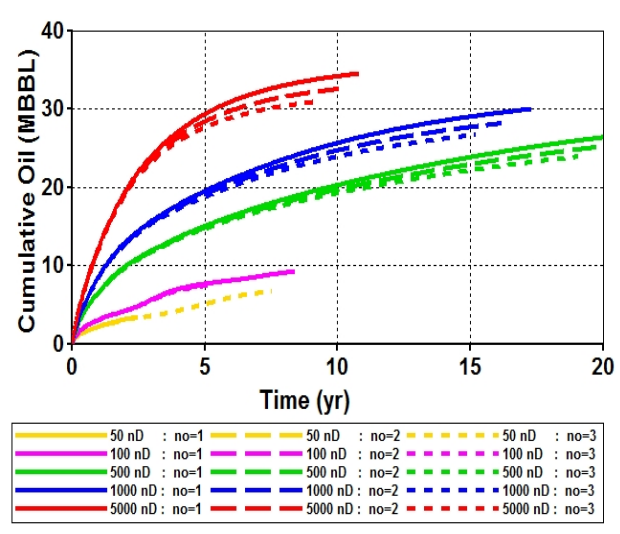

(a)

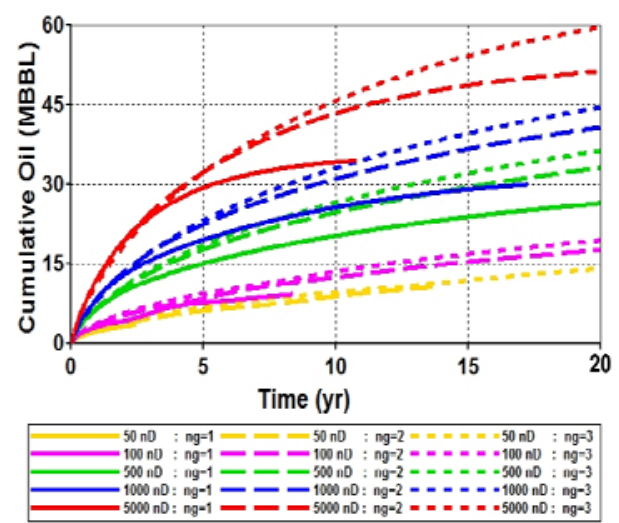

(b)

The curvature varies linear to cubic for both gas and oil relative permeability curves. The complete proportionality of gas and oil, i.e., the straight line curves $\left(n_{0}=1, n_{g}=1\right)$ in Figure 5 are considered as the base case for relative permeability study. When the effect of gas relative permeability is studied, the gas exponent $\left(\mathrm{n}_{\mathrm{g}}\right)$ is varied and the oil exponent $\left(\mathrm{n}_{\mathrm{o}}\right)$ is held constant $\left(\mathrm{n}_{\mathrm{o}}=1\right)$. This is reversed when studying the effect of oil relative permeability. We have plotted the effects of relative permeability and compared the results with base case. The results from lower oil mobility and the base case are compared for all matrix permeabilities in Figure 5.

It is clear from this plot that effect of oil relative permeability at higher matrix permeabilities is noticeable compared to at lower matrix permeabilities as seen in Figure 5(a). Differences in oil production are not very significant for various oil relative permeabilities. The gas relative permeability is kept higher $\left(n_{g}=1\right)$ than oil relative permeability in the study of effect of oil relative permeability. Gas dominates multiphase flow in the reservoir suppressing oil flow because of the higher gas relative permeability 
compared oil relative permeability. Oil relative permeability (in range of $n_{o}=1$ to 3 ) does not affect oil production for low matrix permeability $(50 \mathrm{nD}$ to $500 \mathrm{nD})$ if the gas relative permeability is higher.

Gas relative permeabilities on the other hand have a pronounced impact on oil production as observed in Figure 5(b). Lower gas mobilities can lead to 1.5 times as much oil production over ten years at higher matrix permeabilities. The difference is smaller at lower permeabilities, yet considerable. GORs are also higher when gas relative permeabilities are higher. The observed differences in GORs underscore the difficulty in interpreting production data since gas-oil relative permeabilities are not well known for shales. It is seen that at 'favourable' gas relative permeabilities, the cumulative GORs can be several times the GORs at low gas mobilities.

During the study the effect of gas relative permeability, the oil relative permeability is considered as linear $\left(\mathrm{n}_{\mathrm{o}}=1\right)$ which is higher than gas relative permeability. This fact enhances the flow of oil competing gas, more curvature in gas relative permeability curves, better the cumulative production of oil.

\subsection{Effect of rock compressibility}

It is hypothesised that for ultra-low permeability systems, rock compressibilities have a large effect. This hypothesis was validated when we looked at production from reservoirs with different rock compressibilities, everything else being the same. Effect of rock compressibility in very low porosity (around 5\%) reservoirs like shales is very prominent because compression of rock assures pressure maintenance in the reservoirs. The effects can be significant as seen in Figure 6.

GORs are also much lower with higher rock compressibilities as shown in Figure 6(a). The oil production is about double in ten years when the rock compressibility is 25 times higher as shown in Figure 6(b). These trends were also observed by Orangi et al. (2011). Lower compressibility rocks do not permit the structure to deform; on the other hand, higher compressible rock sustains the pressure of reservoir by squeezing the rock and reducing the pore space for overburden pressure when the pressure in the pore is reduced in course of production. Holding pressure in reservoir helps gas to stay in oil phase as dissolved form, thus, more amount of oil with less GOR is produced on surface.

Figure 6 Impact of compressibilities for matrix permeabilities of $50 \mathrm{nD}$ on (a) cumulative GOR and (b) cumulative oil production (see online version for colours)

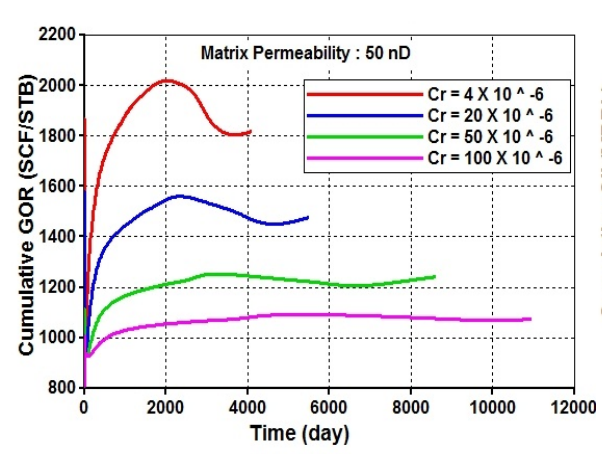

(a)

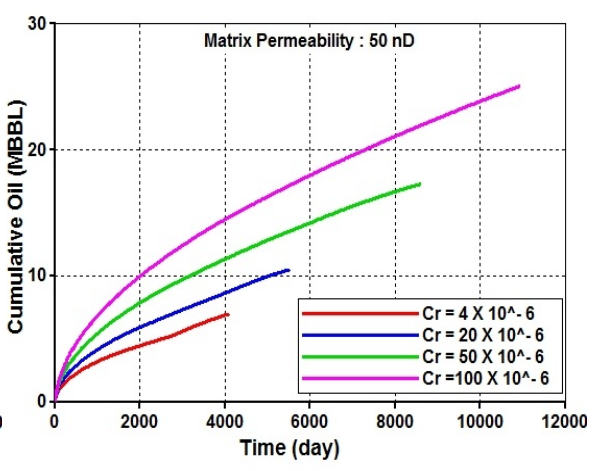

(b) 


\subsection{Effect of fluid properties}

In undersaturated reservoirs, oil fluid properties are important in determining effectiveness of recovery. Effect of fluid properties namely bubble point pressure and initial GOR were studied. In this purpose, five different fluids with pressure-volume-temperature (PVT) properties were chosen as shown in Table 4.

Table 4 Bubble points and solution GORs used in the study

\begin{tabular}{lccc}
\hline$P V T$ & Slope $d R_{s} / d p((S C F / S T B) / p s i)$ & Bubble point pressure $(p s i)$ & $R_{s i}(S C F / S T B)$ \\
\hline 1 & 0.415 & 3,700 & 1,577 \\
2 & 0.247 & 2,800 & 700 \\
3 & 0.415 & 1,700 & 700 \\
4 & 0.710 & 1,000 & 700 \\
5 & 0.415 & 2,800 & 1,152 \\
\hline
\end{tabular}

The GOR ranges from $700 \mathrm{SCF} / \mathrm{STB}$ to around 1,600 SCF/STB and bubble point pressure from 1,000 psi to 3,700 psi. PVT 2, 3 and 4 have same initial GOR $\left(R_{s i}\right)$ but different bubble point pressures. PVT2 and 5 have same bubble point pressure $\left(P_{b p}\right)$ but different initial GORs. PVT1, 3 and 5 have the same slope for solution gas versus pressure $\left(\frac{d R_{s}}{d P}\right)$ but have different bubble point pressures. The effects of bubble point pressure for same initial GOR are shown in Figures 7(a) and 7(b) for matrix permeability of $50 \mathrm{nD}$.

The initial GORs are kept constant at $700 \mathrm{SCF} / \mathrm{STB}$ while the bubble point pressures are changed by varying the slope of GOR with pressure in PVT. As the bubble point pressure is reduced, the oil production decreases and similar trends are observed for higher permeabilities (up to 5,000 nD) too. This trend was unexpected. The quicker transition to two-phase flow with higher bubble point pressure was expected to lower oil recovery. On the contrary, recovery is the highest at the highest bubble point, albeit at higher GORs.

The effect of initial dissolved gas on production is shown in Figure 8.

Figure 7 Effect of bubble point pressure with fixed initial GOR on (a) oil recovery and (b) cumulative GOR (see online version for colours)

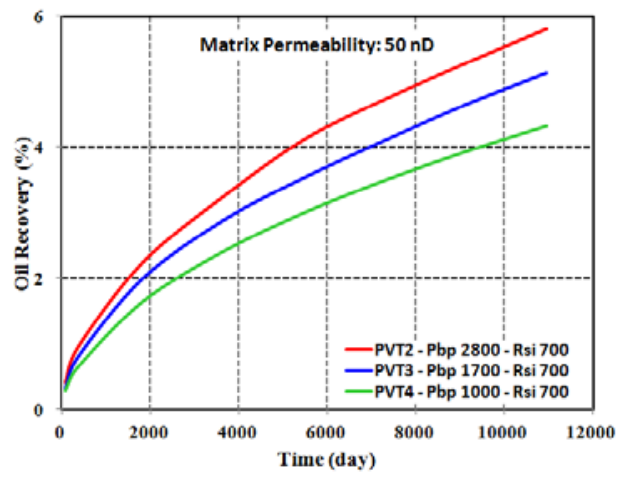

(a)

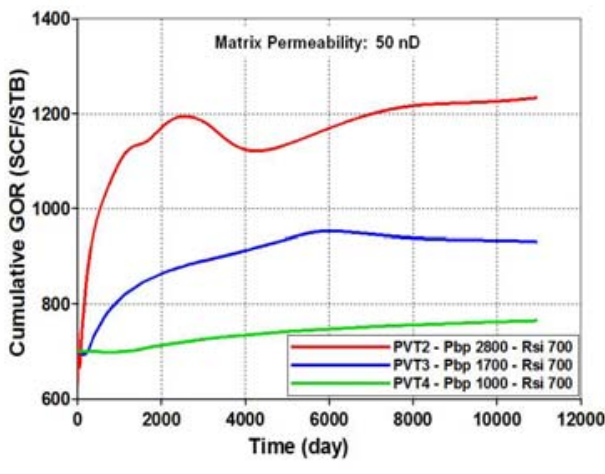

(b) 
Figure 8 Effect of GOR with fixed slope $\mathrm{dR}_{\mathrm{s}} / \mathrm{dp}$ for matrix permeabilities of $50 \mathrm{nD}$ on (a) oil recovery and (b) cumulative GOR (see online version for colours)

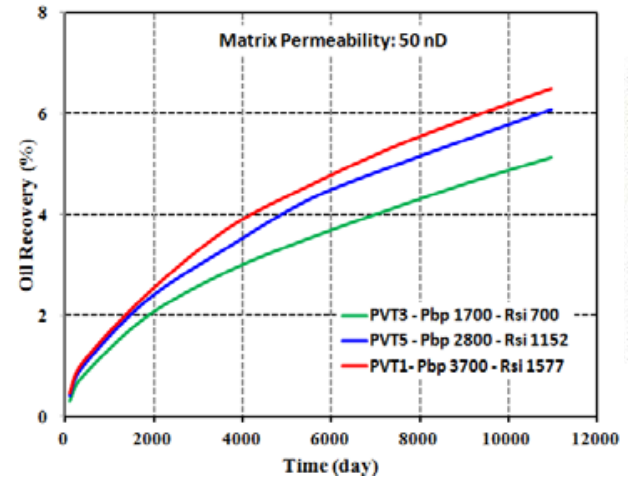

(a)

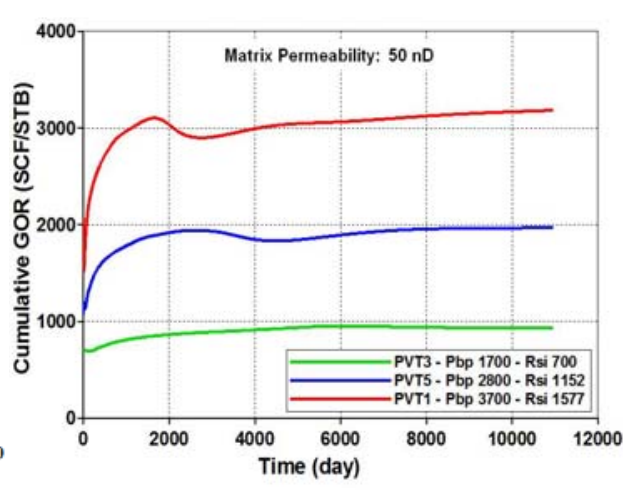

(b)

The higher amount of oil is recovered from higher initial dissolved gas as shown in Figure 8(a) albeit at higher produced GOR [Figure 8(b)]. Produced GOR increases with time as pressure drops in the reservoir. The higher initial dissolved gas provides higher energy for oil production. The higher initial GORs indicate higher bubble point pressure for PVT with fixed slope of GOR with pressure. Transition from undersaturated to saturated condition occurs quicker for higher bubble point pressure as discussed in the previous section. Higher amount of gas dissolved in reservoir also makes oil lighter and improves mobility of oil.

\subsection{Effect of fracture spacing}

Fracture spacing is one of the controllable parameters that could help optimise recovery. Lower fracture spacing provides reservoir access, but will cost more in terms of fracturing costs. The effects of fracture spacing for different reservoir permeablities $(1 \mathrm{nD}$ to $5,000 \mathrm{nD})$ are studied here. The basic parameters of the spacing study are shown in Table 2 and the schematic of the spacing away from the fracture is shown in Figure 1. The idea was that the no-flow boundary would be an actual reservoir boundary or boundary of another fracture for a given spacing. Here recoveries were calculated at the 'abandonment' rate of $1 \mathrm{STB}$ /day. Oil recoveries for different spacing and at different matrix permeabilities are shown in Figures 9(a) and 9(b).

Oil recovery decreases rapidly as fracture spacing increases for $1 \mathrm{nD}$ to $500 \mathrm{nD}$ as shown in Figure 9(a). Recovery stays more or less constant with fracture spacing for $5,000 \mathrm{nD}$ permeability reservoir and recoveries of over $15 \%$ are obtained at spacing between 50 and 150 feet. Levine and Prats (1961) studied the effect of fracture spacing for conventional reservoirs. The plot is reproduced in Figure 9(b). One should be cautious in drawing direct comparisons because the conventional reservoir study was without hydraulic fractures, for a vertical well and a radially draining reservoir. However, it is clear that hydraulically fractured LTO reservoirs in an ideal case have the potential to recover as much or more oil in primary production than the higher permeability conventional reservoirs. 
Figure 9 The effect of permeability on oil recovery, (a) different fracture spacings (b) reproduced from Levine and Prats (1961) (see online version for colours)

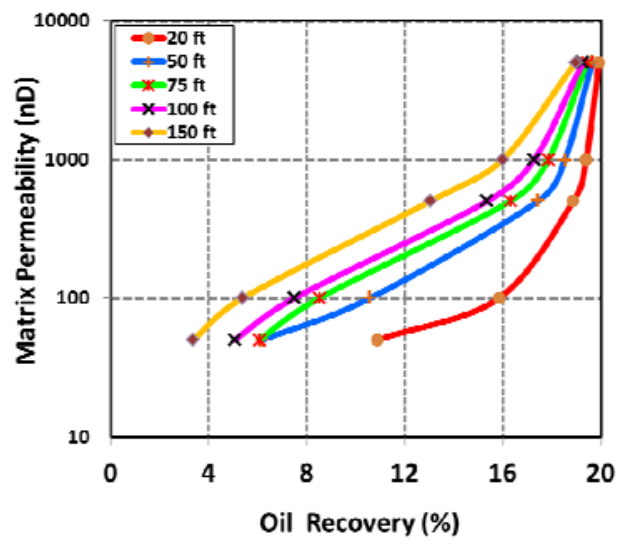

(a)

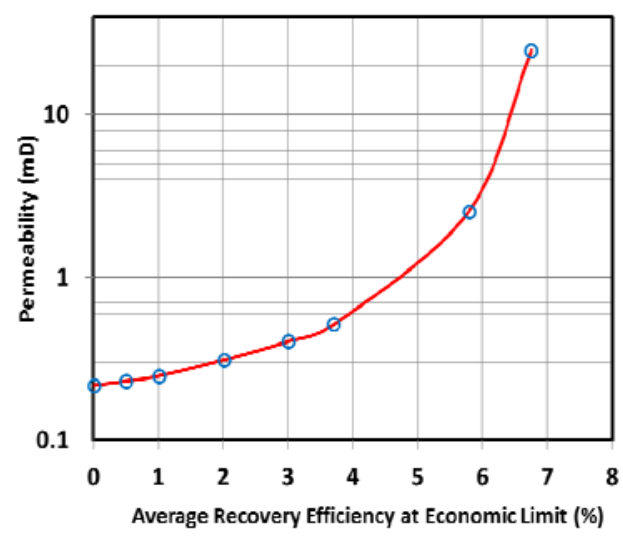

(b)

\subsection{Effect of drawdown and overpressure}

We looked at the effect of drawdown on oil and gas recoveries at two different initial reservoir pressures. Bubble point is kept constant at 2,800 psi for both cases. Oil recoveries were determined at the 'abandonment' rate of $1 \mathrm{STB} /$ day since only one fracture was modelled. Geomechanical effects of fracture closure with drawdown are not considered in these simulations. Oil and gas recoveries are compared for two different initial pressures (4,500 psi and 5,500 psi) in Figures 10(a) and 10(b).

Figure 10 Effect of drawdown and initial reservoir pressures on (a) oil recoveries and (b) gas recoveries (see online version for colours)

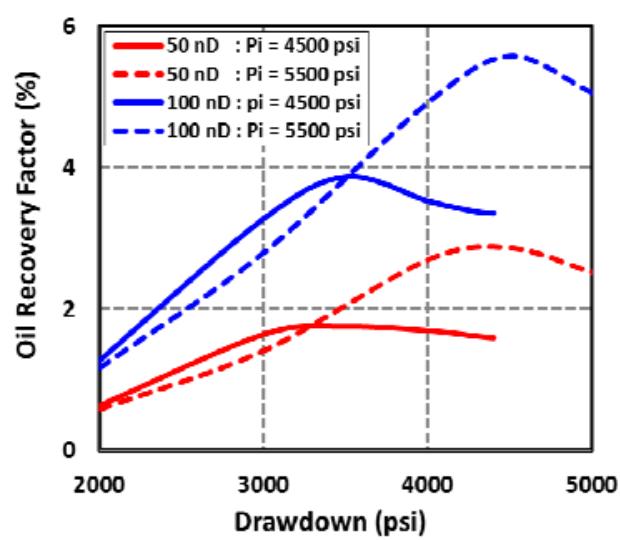

(a)

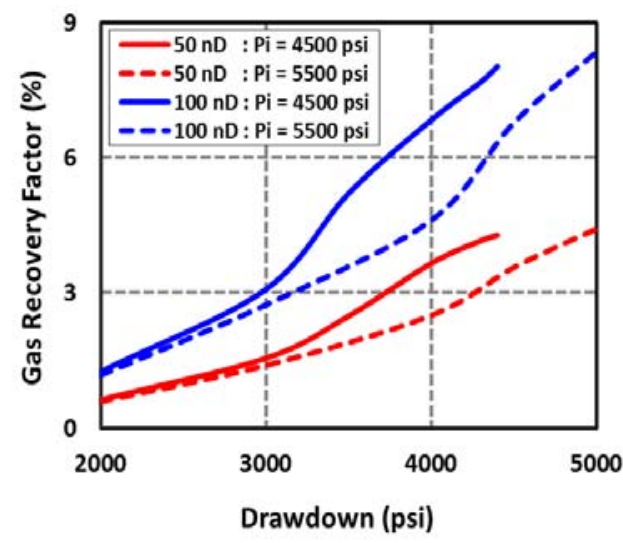

(b)

Oil recoveries from $100 \mathrm{nD}$ reservoir is higher than the $50 \mathrm{nD}$ reservoir as expected but there appear to be optimum with respect to drawdown at lower permeabilities of 50 and $100 \mathrm{nD}$, while the gas recoveries increase monotonically as drawdown increases. 
For same drawdown, more oil is recovered from reservoir with less initial pressure $(4,500 \mathrm{psi})$. Well is operated at higher flowing bottom hole pressure for higher initial pressure $(5,500 \mathrm{psi})$ to maintain same drawdown and less oil is recovered as a result; although, higher optimum recovery is achieved from higher initial pressure reservoir because of long time supply of energy to continue production before reaching the economic rate. The optimum value shifts towards higher drawdowns for higher initial reservoir pressures and for higher permeability $(100 \mathrm{nD})$.

\subsection{Effect of impermeable layers}

Impermeable bentonite layers are found between two shale layers. Layered heterogeneity was studied by inserting impermeable layers (say bentonite) between two permeable layers. Thickness of bentonite layer was one foot and permeability was kept at hundred times less than the formation permeability. Bentonite layer permeability for open fracture (at bentonite layer) is kept same as fracture permeability, and in the case of closed fracture, bentonite layer permeability was used at the fracture. Cumulative oil and GOR for various cases of fracture opening and closing at bentonite layers are analysed in Figure 11 .

Fracture acts as high conductive conduit in reservoirs, when impermeable layers are deposited between two layers; it hinders the vertical cross flow. Oil production is almost same for reservoir (fractured) without any bentonite layers and reservoir with opened fracture at bentonite layers. This result confirms that there is no vertical cross flow between layers and linear flow is established. Gas and oil flow horizontally towards fracture and then are connected through fracture into wells. It is observed that when bentonite layers heal and close at the fracture and assume the permeability of the layer, then the production is reduced significantly. This suggests that fracture closure at bentonite layer isolates the fluid coming to the fracture from adjacent layer, thus, fluid is produced only from the layer adjacent to well. For this case of isolated layer without fracture opening at bentonite layers, drawdown is solely applied to the layer adjacent to the well and higher pressure drop in this layer promotes higher GOR.

Figure 11 Comparison of performances from open and closed fractures, (a) cumulative oil (b) cumulative GOR (see online version for colours)

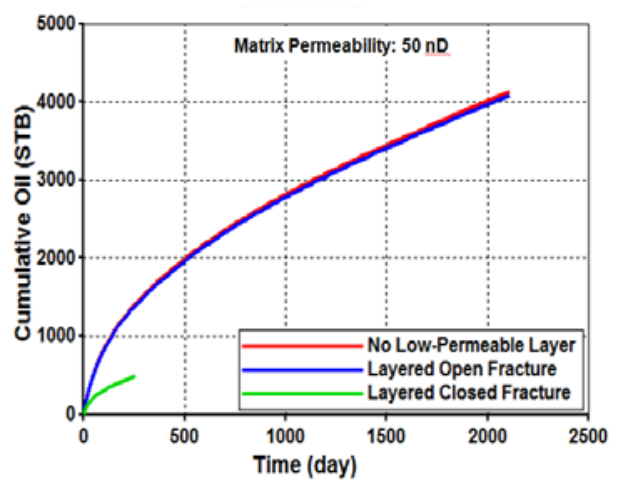

(a)

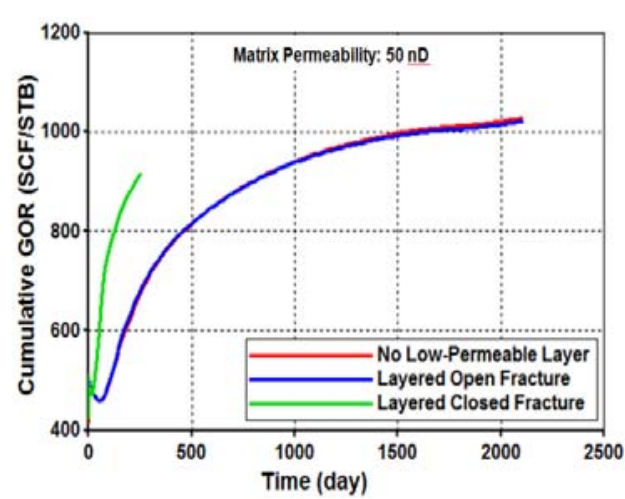

(b) 


\section{Comparison with field data}

Significant contribution in US total tight oil productions comes from Eagle Ford in Texas, Niobrara in Colorado-Wyoming and Bakken in Montana-North Dakota. US Energy Information Administration (EIA) reported that in February 2014, 36\% (1.21 MMSTB/day) and 28\% (0.94 MMSTB/day) of total US tight oil are produced from Eagle Ford and Bakken Shale respectively. Due to very low permeability and porosity, productions from these plays became possible only for horizontal drilling with hydraulic fractures. Field data from these plays are very relevant to compare with simulation results in this study. Oil rate and cumulative GOR are shown in Figures 12 to 14 for Eagle ford, Niobrara and Bakken respectively. It should be noted that the rates are for non-interfering single fracture and net to gross ratio (NTG) is considered as 0.4 for Eagle Ford and 0.6 for Niobrara and Bakken. If there are five clusters per stage in a 16-stage well, with about 80 possible fractures, the rate for a $400 \mathrm{nD}$ reservoir is expected to be between $500 \mathrm{STB} /$ month to about $150 \mathrm{STB} / \mathrm{month}$ in the first year. This depends on the initial dissolved GOR, drawdown, formation compressibility and a number of other factors.

Analysis of the Eagle Ford oil rate indicates that the reservoirs fall within the $50 \mathrm{nD}$ to $100 \mathrm{nD}$ permeability range.

The field oil rates are tightly clustered in $50 \mathrm{nd}$ to $100 \mathrm{nD}$ permeability range and then dipping below the $50 \mathrm{nD}$ simulation results after about a year or so. The GOR values for Eagle Ford are much more variable. The simulation results indicate that for initial GORs of $500 \mathrm{SCF} / \mathrm{STB}$ and 1,000 SCF/STB, the cumulative GORs do not vary much for different permeabilities. At the highest value of the GOR, the lowest permeability yields highest cumulative GOR. Variations in field values span the entire range of initial GORs used in the simulation. These variations appear to be related more to the initial composition of the fluid than to permeability variations.

Figure 12 Comparison of Eagle Ford field data with simulation for (a) oil rate and (b) cumulative GOR (see online version for colours)

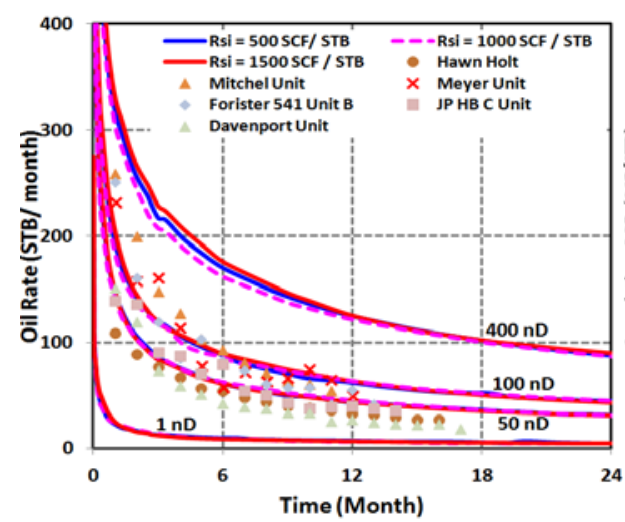

(a)

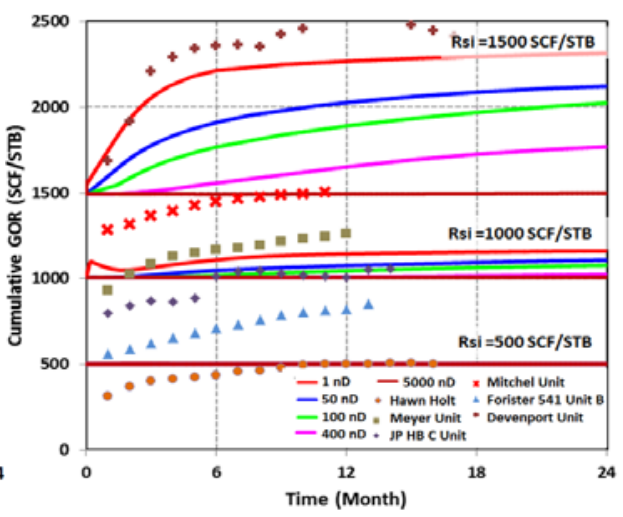

(b) 
Figure 13 Comparison of Niobrara field data with simulation for (a) oil rate and (b) cumulative GOR (see online version for colours)

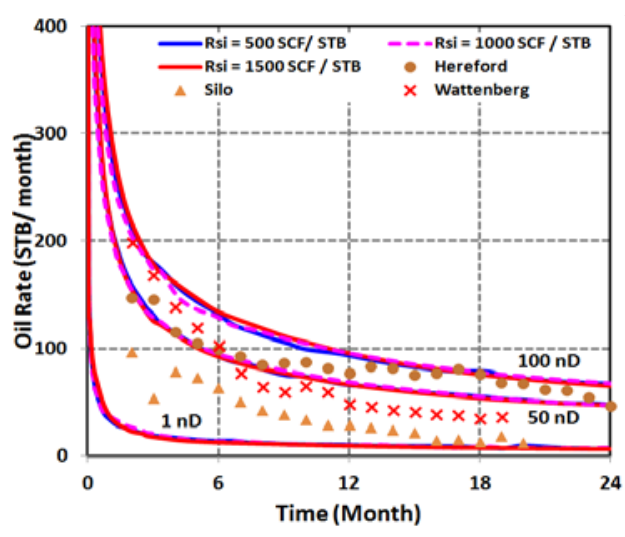

(a)

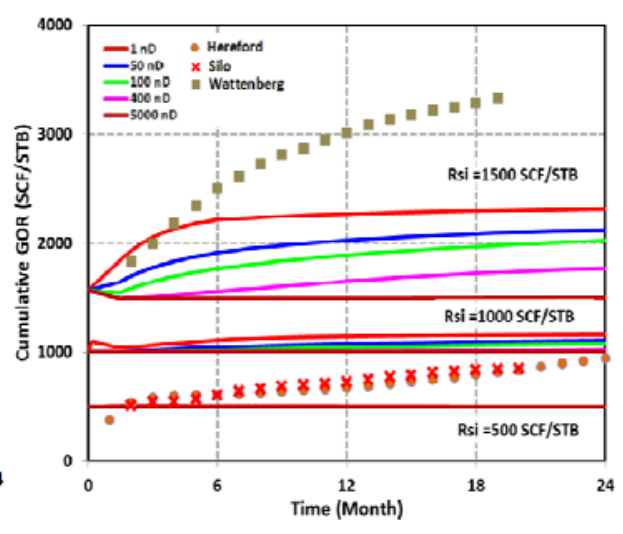

(b)

The Niobrara production rates show a wider variation. This is because the producing compositions and reservoir quality are different for the different formations chosen - Silo, Hereford and Wattenberg. The cumulative GORs however are remarkably consistent. The average cumulative GOR values for Silo and Hereford lie between the initial GOR of 500 to $1,000 \mathrm{SCF} / \mathrm{STB}$. The Wattenberg GORs are higher - most likely due to the initial dissolved GOR being higher.

The Bakken oil rates appear to correspond to higher reservoir permeabilities. These wells are some of the best in the Bakken-Parshall field.

Figure 14 Comparison of Bakken field data with simulation for (a) oil rate and (b) cumulative GOR (see online version for colours)

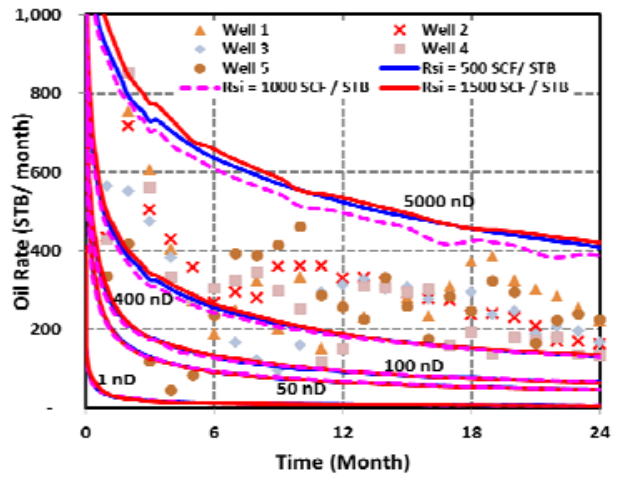

(a)

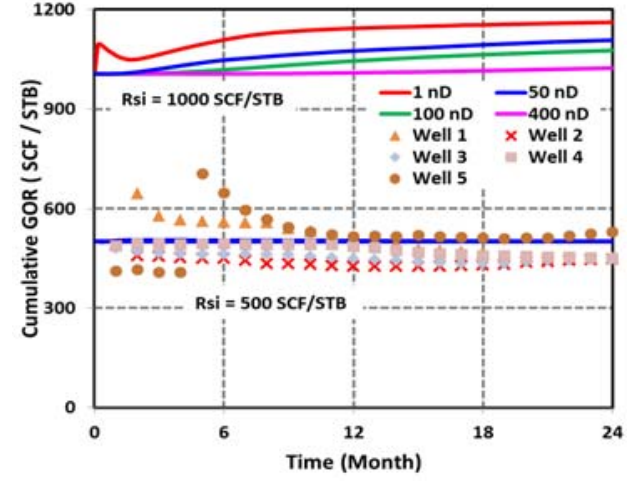

(b) 
The permeabilities to which the field production corresponds to appear to be over $400 \mathrm{nD}$, but less than $5,000 \mathrm{nD}$. This finding is consistent with the 'conventional wisdom' that the Bakken permeabilities - for good wells - are in micro Darcies. The GOR values of these wells stay at the initial solution GOR value of about $550 \mathrm{SCF} / \mathrm{STB}$. It is surprising to see that the GOR does not increase beyond the initial solution GOR indicating that a boundary has not yet been reached.

\section{Conclusions}

Impacts of important geological, fluid properties, operational and completion parameters on oil production from ultra-low permeability reservoirs are investigated. Many important findings appear to be counterintuitive to the current wisdom of production performance from conventional reservoirs. Absolute permeability, relative permeability, formation compressibility, and fracture spacing have the greatest impact on oil recovery.

Oil production increases with increase in reservoir permeability but produced GOR also increases. In ultra-low permeability reservoirs, GOR does not shoot up to many times the initial GOR, but instead stays within two to three times the initial GOR. Effect of gas relative permeability is more pronounced for absolute permeability of more than $100 \mathrm{nD}$. Gas relative permeabilities have more significant impact than oil relative permeabilities. The oil production is higher with more compressible rock. Produced GOR is also reduced for higher compressibility rock. Reduced spacing, generally speaking, results in higher recovery. Spacing has the greatest influence up to $500 \mathrm{nD}$ permeability. It is observed that recovery factor is higher in hydraulically fractured reservoirs in primary production than the recovery from the higher permeability conventional reservoirs, assuming fracture spacing of 100 feet or lower.

For lower drawdowns, less oil and gas are recovered from reservoir with higher initial pressure but at high drawdowns, higher reservoir pressure improves oil and gas recoveries. Optimum oil recoveries are obtained with drawdown for low permeability reservoir $(50 \mathrm{nD}$ and $100 \mathrm{nD})$ although gas recoveries increase monotonically. Higher drawdown generally results in higher recovery - with production at higher GORs. Higher drawdown may also result in fracture closures, even though this geo-mechanical effect was not considered in the simulations. Higher reservoir energy in the form of higher initial dissolved gas is better for oil production. Higher initial dissolved GOR results in higher oil production at higher GORs. Quicker transition to bubble point leads to higher GORs but did not hurt oil production. Impermeable layers like bentonite layers between produced layers reduce recovery when the hydraulic fractures heal and close. 


\section{Nomenclature}

\begin{tabular}{|c|c|c|}
\hline Symbol & Description & Units \\
\hline BHP & Bottom hole pressure & psi \\
\hline$C_{r}$ & Rock compressibility & $1 / \mathrm{psi}$ \\
\hline GOR & Gas oil ratio & $\mathrm{SCF} / \mathrm{STB}$ \\
\hline$k_{r g}$ & Gas relative permeability & - \\
\hline$k_{\text {rog }}$ & Oil relative permeability in gas-oil system & - \\
\hline$k_{\text {row }}$ & Oil relative permeability in water-oil system & - \\
\hline$k_{r w}$ & Water relative permeability & - \\
\hline$k_{f x}$ & Fracture permeability in X-direction & $\mathrm{mD}$ \\
\hline$k_{f y}$ & Fracture permeability in Y-direction & $\mathrm{mD}$ \\
\hline$k_{f z}$ & Fracture permeability in Z-direction & $\mathrm{mD}$ \\
\hline$n_{g}$ & Exponent of on relative permeability curve for gas & - \\
\hline$n_{o}$ & Exponent of on relative permeability curve for oil & - \\
\hline$n_{w}$ & Exponent of on relative permeability curve for water & - \\
\hline NTG & Net to gross ratio & - \\
\hline$P_{b p}$ & Bubble point pressure & psi \\
\hline$P_{i}$ & Initial reservoir pressure & psi \\
\hline$R_{s}$ & Gas oil ratio & $\mathrm{SCF} / \mathrm{STB}$ \\
\hline$R_{s i}$ & Initial gas oil ratio & $\mathrm{SCF} / \mathrm{STB}$ \\
\hline$S^{*}$ & Effective saturation & - \\
\hline$S_{g}$ & Gas saturation & - \\
\hline$S_{g c}$ & Critical gas saturation & - \\
\hline$S_{\text {org }}$ & Residual oil saturation in gas-oil system & - \\
\hline$S_{\text {orw }}$ & Residual oil saturation in water-oil system & - \\
\hline$S_{w}$ & Water saturation & - \\
\hline$S_{w c}$ & Connate water saturation & - \\
\hline
\end{tabular}

\section{References}

Chaudhary, A.S., Ehlig-Economides, C.A. and Wattenbarger, R.A. (2011) 'Shale oil production performance from a stimulated reservoir volume', SPE Annual Technical Conference and Exhibition, Society of Petroleum Engineers, Denver, Colorado, USA.

Clemens, T. and Wit, K. (2001) 'The effect of fracture spacing on gas/oil gravity drainage in naturally fractured reservoirs', SPE Annual Technical Conference and Exhibition, Society of Petroleum Engineers, New Orleans, Louisiana.

Evinger, H.H. and Muskat, M. (1942) 'Calculation of theoretical productivity factor', Transactions of the AIME, Vol. 146, No. 1, pp.126-139, 942126-G.

Hall, H.N. (1953) 'Compressibility of reservoir rocks', Journal of Petroleum Technology, Vol. 5, No. 1, pp.309-311.

Hernandez, J.C., Vesovic, V., Carter, J.N. and Lopez, E. (2002) 'Sensitivity of reservoir simulations to uncertainties in viscosity', SPE/DOE Improved Oil Recovery Symposium, Society of Petroleum Engineers, Tulsa, Oklahoma. 
Levine, J.S. and Prats, M. (1961) 'The calculated performance of solution-gas-drive reservoirs', Society of Petroleum Engineers Journal, Vol. 1, No. 3, pp.142-152, 1520-G.

Ling, K. and Shen, Z. (2011) 'Effects of fluid and rock properties on reserves estimation', SPE Eastern Regional Meeting, Society of Petroleum Engineers, Columbus, Ohio, USA.

Orangi, A., Nagarajan, N.R., Honarpour, M.M. and Rosenzweig, J.J. (2011) 'Unconventional shale oil and gas-condensate reservoir production, impact of rock, fluid, and hydraulic fractures', SPE Hydraulic Fracturing Technology Conference, Society of Petroleum Engineers, The Woodlands, Texas, USA.

Panja, P., Conner, T. and Deo, M. (2013) 'Grid sensitivity studies in hydraulically fractured low permeability reservoirs', Journal of Petroleum Science and Engineering, Vol. 112, pp.78-87.

Steffensen, R.J. (1987) 'Solution-gas-drive reservoirs', in Howard B. Bradley (Ed.): Petroleum Engineering Handbook, Chap. 37, Richardson, Society of Petroleum Engineers, Texas.

Vogel, J.V. (1968) 'Inflow performance relationships for solution-gas drive wells', Journal of Petroleum Technology, Vol. 20, No. 1, pp.83-92, Society of Petroleum Engineers. 